\title{
Acceleration of Convergence of One Iterative Method for Finding the Roots of Equations
}

\author{
Dragomir M. Simeunović
}

Abstract. In this paper we consider two iterative methods which accelerate the finding of the roots of equations.

It is well known that, if the equation

$$
x=f(x)
$$

has only one root $x=r$ in the interval $[a, b]$, and if the derivative $f^{\prime}(x)$ of the function $f(x)$ satisfies the condition

$$
\max \left|f^{\prime}(x)\right|=M<1, \quad \text { for } x \in[a, b],
$$

then the iterative method

$$
x_{k+1}=f\left(x_{k}\right), \quad k=0,1,2 \ldots,
$$

converges to the root $x=r$ of the equation (1), where the initial value $x_{0}$ can be any number from the interval $[a, b]$. The convergence of method (3) is more rapid if $M$ has a small value.

In this paper we consider the values $f^{\prime}(a)$ and $f^{\prime}(b)$ and use it to determine $\max \left|f^{\prime}(x)\right|$.

We consider two iterative methods for finding the root $x=r$ of the equation (1) in cases when

$$
\begin{aligned}
& f^{\prime}(a) \neq 0, \quad f^{\prime}(b) \neq 0 \\
& \max \left|f^{\prime}(x)\right|=M<1
\end{aligned}
$$

and when $f^{\prime}(x)$ is increasing or decreasing.

If the conditions (4) and (5) are satisfied, then

$$
\left|f^{\prime}(a)\right|<1 \text { and }\left|f^{\prime}(b)\right|<1 .
$$

We put

$$
f^{\prime}(a)=\alpha, \quad f^{\prime}(b)=\beta .
$$

Because of (6) and (7), we have

$$
1-\alpha>0 \text { and } 1-\beta>0 .
$$

2010 Mathematics Subject Classification. Primary: 65H05.

Key words and phrases. Iteration formulas, approximate solutions of equations. 
If the function $f^{\prime}(x)$ is increasing on the interval $[a, b]$, then we consider the following two cases

$$
\begin{gathered}
-1<\alpha \leq f^{\prime}(x) \leq \beta<0, \\
0<\alpha \leq f^{\prime}(x) \leq \beta<1 .
\end{gathered}
$$

In these cases, we write the equation (1) in the form

$$
x=\frac{1}{1-\alpha}(f(x)-\alpha x),
$$

that is, in the form

$$
x=f_{1}(x),
$$

where

$$
f_{1}(x)=\frac{1}{1-\alpha}(f(x)-\alpha x) .
$$

From (11) we obtain

$$
f_{1}^{\prime}(x)=\frac{1}{1-\alpha}\left(f^{\prime}(x)-\alpha\right) .
$$

As $f^{\prime}(x)$ is an increasing function, considering (8), we conclude from (12) that the function $f_{1}^{\prime}(x)$ is also increasing.

For the case $\left(C_{1}\right)$, we have

$$
\max \left|f^{\prime}(x)\right|=|\alpha|
$$

Considering (7), we obtain from (12)

$$
f_{1}^{\prime}(a)=0, \quad f_{1}^{\prime}(b)=\frac{\beta-\alpha}{1-\alpha}<\frac{|\alpha|}{1+|\alpha|}<|\alpha| .
$$

From (14) we conclude that

$$
\max \left|f_{1}^{\prime}(x)\right|=\frac{\beta-\alpha}{1-\alpha}<\frac{|\alpha|}{1+|\alpha|}<|\alpha| .
$$

For the case $\left(C_{2}\right)$, we have

$$
\max \left|f^{\prime}(x)\right|=\beta .
$$

Considering (7), we obtain from (12)

$$
f^{\prime}(a)=0, \quad f^{\prime}(b)=\frac{\beta-\alpha}{1-\alpha} .
$$

From (17) we conclude that

$$
\max \left|f_{1}^{\prime}(x)\right|=\frac{\beta-\alpha}{1-\alpha}<\beta .
$$

When $f^{\prime}(x)$ is decreasing, we consider the other two cases

$$
\begin{aligned}
& 0>\alpha \geq f^{\prime}(x) \geq \beta>-1, \\
& 1>\alpha \geq f^{\prime}(x) \geq \beta>0 .
\end{aligned}
$$


In these cases, we write the equation (1) in the form

$$
x=\frac{1}{1-\beta}(f(x)-\beta x),
$$

that is, in the form

$$
x=f_{2}(x),
$$

where

$$
f_{2}(x)=\frac{1}{1-\beta}(f(x)-\beta x) .
$$

From (21) we obtain

$$
f_{2}^{\prime}(x)=\frac{1}{1-\beta}\left(f^{\prime}(x)-\beta\right) .
$$

As $f^{\prime}(x)$ is a decreasing function, considering (8), we conclude from (22) that the function $f_{2}^{\prime}(x)$ is also decreasing.

For the case $\left(C_{3}\right)$, we have

$$
\max \left|f^{\prime}(x)\right|=|\beta| .
$$

In view of (7), we obtain from (22)

$$
f_{2}^{\prime}(a)=\frac{\alpha-\beta}{1-\beta}<\frac{|\beta|}{1+|\beta|}<|\beta|, \quad f_{2}^{\prime}(b)=0 .
$$

From (24) we conclude that

$$
\max \left|f_{2}^{\prime}(x)\right|=\frac{\alpha-\beta}{1-\beta}<|\beta| .
$$

For the case $\left(C_{4}\right)$, we have

$$
\max \left|f^{\prime}(x)\right|=\alpha .
$$

In view of (7), we obtain from (22)

$$
f_{2}^{\prime}(a)=\frac{\alpha-\beta}{1-\beta}<\alpha, \quad f_{2}^{\prime}(b)=0 .
$$

From (27) we conclude that

$$
\max \left|f_{2}^{\prime}(x)\right|=\frac{\alpha-\beta}{1-\beta}<\alpha .
$$

From the conditions (4), (5) and (7), as well as from (13), (15) and (16), (18), we see that

$$
\max \left|f_{1}^{\prime}(x)\right|<\max \left|f^{\prime}(x)\right|
$$

when $f^{\prime}(x)$ is increasing, which satisfies $\left(C_{1}\right)$ or $\left(C_{2}\right)$. Then, from (9) we obtain the iterative method

$$
x_{k+1}=\frac{1}{1-\alpha}\left(f\left(x_{k}\right)-\alpha x_{k}\right), \quad k=0,1,2 \ldots .
$$


Analogously, from the conditions (4), (5) and (7), as well as from (23), (25) and (26), (28), we see that

$$
\max \left|f_{2}^{\prime}(x)\right|<\max \left|f^{\prime}(x)\right|
$$

when $f^{\prime}(x)$ is decreasing, which satisfies $\left(C_{3}\right)$ or $\left(C_{4}\right)$. Then from (19) we obtain the iterative method

$$
x_{k+1}=\frac{1}{1-\beta}\left(f\left(x_{k}\right)-\beta x_{k}\right), \quad k=0,1,2 \ldots .
$$

Because of (29) and (31), the method (30) or the method (32) converges more rapidly than the method (3).

We demonstrate the methods (31) and (32) on the following examples.

Example 1. The equation

$$
x^{3}-8 x+5=0
$$

has only one root $x=r$ in the interval $[2,3]$.

We can write the equation $(A)$ in the form

$$
x=\frac{8}{x}-\frac{5}{x^{2}}
$$

that is, in the form

$$
x=f(x),
$$

where

$$
f(x)=\frac{8}{x}-\frac{5}{x^{2}}
$$

From $\left(A_{3}\right)$ we obtain

$$
f^{\prime}(x)=-\frac{8}{x^{2}}+\frac{10}{x^{3}}
$$

On $[2,3]$ the function $f^{\prime}(x)$ is increasing, and

$$
\left(A_{5}\right) \quad f^{\prime}(a)=f^{\prime}(2)=\alpha=-\frac{3}{4}=-0.75, \quad f^{\prime}(b)=f^{\prime}(3)=\beta=-\frac{14}{27},
$$

which means that we can apply the formula (30) in the case $\left(C_{1}\right)$. According to (13), from $\left(A_{5}\right)$ we have

$$
\max \left|f^{\prime}(x)\right|=|\alpha|=0.75
$$

and according to (15), we have from $\left(A_{5}\right)$

$$
\max \left|f_{1}^{\prime}(x)\right|=\frac{\beta-\alpha}{1-\alpha}=0.132275132 .
$$

Now, the formul; a (30) is reduced to

$$
x_{k+1}=\frac{1}{1.75}\left(\frac{8}{x_{k}}-\frac{5}{x_{k}^{2}}+0.75 x_{k}\right), \quad k=0,1,2, \ldots,
$$


and the formula (3) to

$$
x_{k+1}=\frac{8}{x_{k}}-\frac{5}{x_{k}^{2}}, \quad k=0,1,2 \ldots .
$$

The values $x_{k}$ are listed in Table 1. Both formulas $\left(A_{6}\right)$ and $\left(A_{7}\right)$ start from the same initial value $x_{0}=3$.

TABLE 1 .

\begin{tabular}{|l|l|}
\hline Formula $\left(A_{6}\right)$ & Formula $\left(A_{7}\right)$ \\
\hline \hline$x_{0}=3$ & $x_{0}=3$ \\
$x_{1}=2.492063492$ & $x_{1}=2.111111111$ \\
$x_{2}=2.442362884$ & $x_{2}=2.667590028$ \\
$x_{3}=2.296323254$ \\
$x_{3}=2.439477086$ & $x_{5}=2.377364738$ \\
$x_{4}=2.439320604$ & $\ldots \ldots \ldots \ldots \ldots$ \\
$x_{5}=2.439312154$ & $x_{10}=2.446868841$ \\
$x_{6}=2.439311698$ & $x_{20}=2.439422287$ \\
$x_{7}=2.439311673$ & $x_{30}=2.439313292$ \\
$x_{8}=2.439311672$ & $x_{40}=2.439311695$ \\
$x_{9}=2.439311672$ & $x_{50}=2.439311672$ \\
$x_{51}=2.439311672$ \\
\hline
\end{tabular}

Example 2. The equation

$$
x+e^{x}-2=0
$$

has only one root $x=r$ in the interval [0,0.8].

We can write the equation $(B)$ in the form

$$
x=\ln (2-x),
$$

that is, in the form

$$
x=f(x),
$$

where

$$
f(x)=\ln (2-x) .
$$

From $\left(B_{3}\right)$ we obtain

$$
f^{\prime}(x)=\frac{1}{x-2} .
$$

On $[0,0.8]$ the function $f^{\prime}(x)$ is decreasing, and

$$
\left(B_{5}\right) \quad f^{\prime}(a)=f^{\prime}(0)=\alpha=-\frac{1}{2}, \quad f^{\prime}(b)=f^{\prime}(0.8)=\beta=-\frac{5}{6},
$$


which means that we can apply the formula (32) in the case $\left(C_{3}\right)$. According to (23), from $\left(B_{5}\right)$ we have

$$
\max \left|f^{\prime}(x)\right|=|\beta|=\frac{5}{6}
$$

and according to (25), we have from $\left(B_{5}\right)$

$$
\max \left|f_{2}^{\prime}(x)\right|=\frac{\beta-\alpha}{1-\beta}=0.181818182 .
$$

Now, the formula (32) is reduced to

$$
x_{k+1}=\frac{1}{11}\left(6 \ln \left(2-x_{k}\right)+5 x_{k}\right), \quad k=0,1,2, \ldots,
$$

and the formula (3) to

$$
x_{k+1}=\ln \left(2-x_{k}\right), \quad k=0,1,2 \ldots .
$$

\begin{tabular}{|c|c|}
\hline Formula $\left(B_{6}\right)$ & Formula $\left(B_{7}\right)$ \\
\hline$x_{0}=0.8$ & $x_{0}=0.8$ \\
\hline$x_{1}=0.463084485$ & $x_{1}=0.182321557$ \\
\hline$x_{2}=0.444917036$ & $x_{2}=0.597560106$ \\
\hline & $x_{3}=0.338213501$ \\
\hline$x_{3}=0.44306896$ & $x_{5}=0.400189062$ \\
\hline$x_{4}=0.442876765$ & $\cdots \cdots \cdots \cdots$ \\
\hline$x_{5}=0.442856732$ & $x_{20}=0.442909554$ \\
\hline$x_{6}=0.442854644$ & $x_{30}=0.442853978$ \\
\hline$x_{7}=0.442854426$ & $\cdots \cdots=0.442854409$ \\
\hline$x_{8}=0.442854404$ & $\cdots \cdots \cdots \cdots \cdots$ \\
\hline$x_{9}=0.442854401$ & $x_{47}=0.442854401$ \\
\hline$x_{10}=0.442854401$ & $x_{48}=0.442854401$ \\
\hline
\end{tabular}

The values $x_{k}$ are listed in Table 2. Both formulas $\left(B_{6}\right)$ and $\left(B_{7}\right)$ start from the same initial value $x_{0}=0.8$.

TABLE 2 .

REFERENCES

[1] Б.П. Демидович, И.А. Марон, Основы вычислительной математики (in Russian), Наука, Москва, 1970.

[2] Đuro Kurepa, Viša Algebra, 2. knjiga, Zavod za izdavanje udžbenika, Beograd, 1970.

Dragomir M. Simeunović Mike Alasa 8 